\title{
GFP as a marker for transient gene transfer and expression in Mycoplasma hyorhinis
}

\author{
Hassan Z. A. Ishag 1,2, Maojun Liu'', Ruosong Yang ${ }^{1}$, Qiyan Xiong ${ }^{1}$, Zhixin Feng ${ }^{1}$ and Guoging Shao ${ }^{1 *}$
}

\begin{abstract}
Mycoplasma hyorhinis (M. hyorhinis) is an opportunistic pathogen of pigs and has been shown to transform cell cultures, which has increased the interest of researchers. The green florescence proteins (GFP) gene of Aquorea victoria, proved to be a vital marker to identify transformed cells in mixed populations. Use of GFP to observe gene transfer and expression in M. hyorhinis (strain HUB-1) has not been described. We have constructed a pMD18-O/MHRgfp plasmid containing the $p 97$ gene promoter, origin of replication, tetracycline resistance marker and GFP gene controlled by the $p 97$ gene promoter. The plasmid transformed into $M$. hyorhinis with a frequency of $\sim 4 \times 10^{-3} \mathrm{cfu} / \mu \mathrm{g}$ plasmid DNA and could be detected by PCR amplification of the GFP gene from the total DNA of the transformant mycoplasmas. Analysis of a single clone grown on KM2-Agar containing tetracycline, showed a green fluorescence color. Conclusively, this report suggests the usefulness of GFP to monitor transient gene transfer and expression in $M$. hyorhinis, eventually minimizing screening procedures for gene transfer and expression.
\end{abstract}

Keywords: Mycoplasma hyorhinis, Plasmid, GFP, Expression

Mycoplasma hyorhinis (M. hyorhinis) is a commensal pathogen of swine that also causes lung lesions and inflammation (Razin et al. 1998), and is thought to contribute to the development of cell transformation in vitro (Namiki et al. 2009). These properties of M. hyorhinis have increased interest to the researchers.

Whole genome sequence of $M$. hyorhinis strain HUB-1 was determined (Liu et al. 2010), and expression of foreign antigens in $M$. hyorhinis might help to produce recombinant engineered strains. However, a method based on GFP expressing plasmids to evaluate the transformation and expression of foreign genes in $M$. hyorhinis has not been described. Several methods to monitor gene activity in cells are available such as the formation of fusion proteins with coding sequences for $\beta$-galactosidase, firefly luciferase, and bacterial luciferase (Stewart and Williams 1992). But, these methods are of

\footnotetext{
*Correspondence: gqshaojaas@163.com

${ }^{1}$ Institute of Veterinary Medicine, Jiangsu Academy of Agricultural

Sciences, Key Laboratory of Veterinary Biological Engineering

and Technology, Ministry of Agriculture, National Research Center

for Engineering and Technology of Veterinary Bio-products,

Nanjing 210014, China

Full list of author information is available at the end of the article
}

limited use since they require exogenous substrates or cofactors. The green florescence proteins (GFP) of jellyfish Aequorea victoria is a unique tool to monitor gene transfer and expression (Cubitt et al. 1995). Using GFP might help to construct an efficient reporter system for $M$. hyorhinis. Here, we constructed a plasmid expressing GFP fluorescence and optimized conditions for transformation by electroporation.

M. hyorhinis strain HUB-1 (GenBank accession CP002170.1) was provided by Prof. Xiao Shaobo (Huazhong Agricultural University, China) and was grown at $37^{\circ} \mathrm{C}$ in $\mathrm{KM} 2$ cell-free liquid medium (a modified Friis medium) containing $20 \%(\mathrm{v} / \mathrm{v})$ swine serum (Xiong et al. 2016). KM2-Agar was prepared by adding $0.7 \%$ Agar (Biowest Agarose ${ }^{\circledR} \mathrm{G}-10$; Gene Company Limited, Chi Wan, Hong Kong) to KM2 medium and was incubated at $37^{\circ} \mathrm{C}$ to grow the visible colonies. Tetracycline hydrochloride (Sigma-Aldrich) was used at $0.01 \mu \mathrm{g} /$ $\mathrm{ml}$.

We previously constructed a plasmid pMD18-TOgfp encoding tetracycline resistance gene (tet $M)$ controlled by the $p 97$ gene promoter, GFP gene also controlled by the $p 97$ gene promoter and oriC of $M$. hyopneumoniae attenuated strain (168L) (GenBank accession 507382422) 


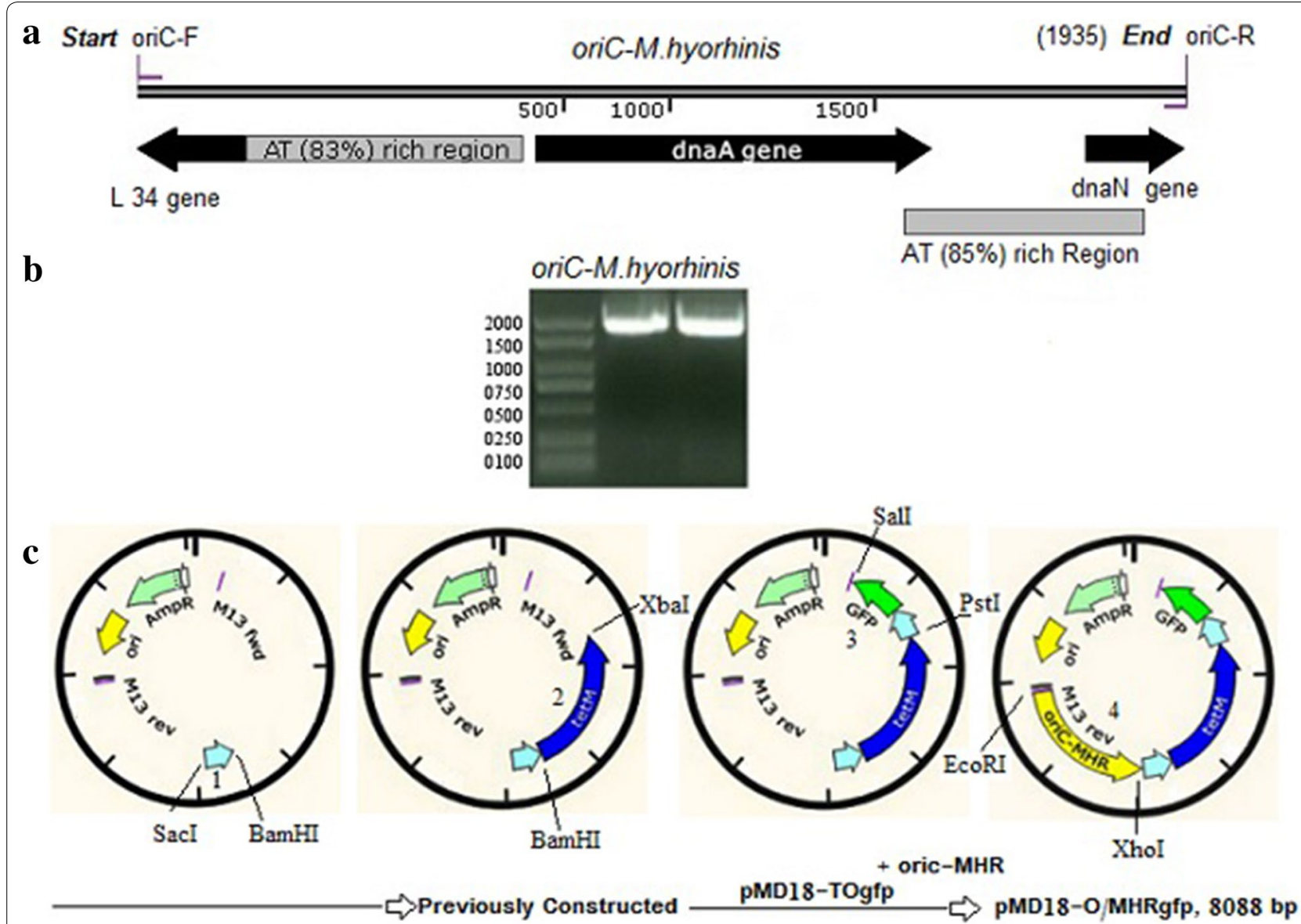

Fig. 1 Construction of pMD18-O/MHRgfp. a The predicted origin of replication (oriC) of M. hyorhinis (strain HUB-1). b PCR amplified oriC fragment (1935 bp). c Diagram and map of pMD18-O/MHRgfp construction. The oriC of M. hyopneumoniae strain 186L was removed from pMD18-TOgfp with EcoRl and Xhol restriction enzymes and replaced with oriC of $M$. hyorhinis. Numbers 1,2,3 and 4 indicated the order of the fragments cloned into the vector

(Ishag et al. 2016). The purpose of this plasmid was to express GFP in M. hyopneumoniae strain 168L. It is well known that, the $p 97$ gene functions as an adhesion molecule for M. hyopneumoniae and the activity of this promoter was previously described in oriC-plasmids of M. hyopneumoniae (Maglennon et al. 2013). Here, we further evaluated the potential of this promoter in $M$. hyorhinis.

The presence of the oriC in plasmids is necessary to maintain the plasmid in the host, and for mycoplasmas, the oriC has been found to be species specific (Cordova et al. 2002). To construct a specific system expressing GFP in M. hyorhinis, we predicted the oriC of M. hyorhinis strain HUB-1 (Fig. 1a) following previously methods described in M. hyoneumoniae (Maglennon et al. 2013). The oriC was PCR amplified from the DNA of $M$. hyorhinis (Fig. 1b) using oriC primers listed in Table 1 and was used to replace the oriC of $M$. hyoneumoniae in the vector pMD18-TOgfp at EcoRI and XhoI restriction sites. The resulting plasmid specific for $M$. hyorhinis was designated pMD18-O/MHRgfp. The diagram of the initial cloning and introduction of a new oriC is shown in (Fig. 1c). The cloning was verified by restriction enzyme digestion and DNA sequence analysis.

Transformation of $M$. hyorhinis by polyethylene glycol (PEG) was reported (Dybvig and Alderete 1988). Here, we optimized methods for transformation by electroporation (Maglennon et al. 2013): We obtained no clones in the KM2-Agar plate containing $0.01 \mu \mathrm{g} / \mathrm{ml}$ tetracycline hydrochloride when we used low voltage $(1-1.5 \mathrm{kV})$ or low concentrations of plasmid DNA $(1-5 \mu \mathrm{g})$. However, increasing the voltage directly to $2.5 \mathrm{kV}$ and the amount of plasmid DNA to $15 \mu \mathrm{g}$ could produce $4 \times 10^{-3} \mathrm{cfu} / \mu \mathrm{g}$ plasmid DNA. Briefly, $40 \mathrm{ml}$ of $M$. hyorhinis culture were centrifuged at $12,000 \mathrm{rpm}$ for $20 \mathrm{~min}$ at $4{ }^{\circ} \mathrm{C}$, and the pellet was washed three times with electroporation buffer 
Table 1 Primers used to amplify the oriC of $M$. hyorhinis to construct pMD18-O/MHRgfp plasmid

\begin{tabular}{llll}
\hline Fragment & Enzymes & Oligonucleotides sequence $\left(\mathbf{5}^{\prime} \mathbf{-} \mathbf{3}^{\prime}\right)$ & Product (bp) \\
\hline oriC-MHR & ECOR1 & Forward: CCGGTGAATTCTACCTTTTGCTCTTCTTGCTGCTA & 1935 \\
& Xhol & Reverse: CGAACTCGAGTAGGAGGATTTCGTCTTATAGG & \\
\hline
\end{tabular}

Restriction enzyme sites are in bold and underlined

MHR, M. hyorhinis

(272 mM Sucrose, $200 \mathrm{mM}$ HEPES pH 7.2) supplemented with $1 \mathrm{mM}$ EDTA. The product was incubated on ice for $5 \mathrm{~min}$, and resuspended in $100 \mu \mathrm{l}$ of electroporation buffer. Plasmid DNA $(15 \mu \mathrm{g})$ was added to $100 \mu \mathrm{l}$ competent cells and transferred to chilled $0.2 \mathrm{~cm}$ electroporation cuvette (Bio-Rad, USA). The mixture was incubated on ice for $20 \mathrm{~min}$. The cells were electroporated on $\mathrm{ECM}^{\circledR}$ 630 Electroporation System, BTX ${ }^{\mathrm{TM}}$ at $2.5 \mathrm{kV}, 125 \Omega$ and $25 \mu \mathrm{F}$. Immediately after electroporation, $900 \mu \mathrm{l}$ of chilled KM2 medium was added and incubated for $20 \mathrm{~min}$ on ice and then recovered for $3 \mathrm{~h}$ at $37^{\circ} \mathrm{C}$. The culture was diluted, plated on KM2 plates containing $0.7 \%$ Agar and $0.01 \mu \mathrm{g} / \mathrm{ml}$ of tetracycline hydrochloride and incubated at $37{ }^{\circ} \mathrm{C}$ until growth of visible clones. Tetracyclineresistant colonies of transformed mycoplasmas grown on KM2-Agar had appeared within 3-10 days of incubation (Fig. 2a). These colonies were absent in the control mycoplasmas that were not electroporated with plasmid.

Tetracycline-resistant mycoplasmas were analyzed for their plasmid content. Total genomic DNA was extracted using a TIANamp Bacteria DNA Kit (Tiangen, Beijing, China) from either the pool of mycoplasma cultures containing $0.01 \mu \mathrm{g} / \mathrm{ml}$ tetracycline hydrochloride or from a single resistant clone sub-cultured in KM2 medium containing $0.01 \mu \mathrm{g} / \mathrm{ml}$ tetracycline hydrochloride. The presence of pMD18-O/MHRgfp was analyzed by the detection of GFP (750 bp) by PCR, and GFP could be detected from the total genomic DNA of the transformants, but not from untransformed mycoplasmas (Fig. 2b). One product amplified with GFP specific primers was sequenced and was indeed the expected GFP sequence (data not shown).

Expression of GFP in a single clone of $M$. hyorhinis selected on KM2-Agar was also studied. Seven day-old colonies showed green fluorescence when observed by fluorescence microscopy (Nikon, Eclipse E600, Tokyo, Japan) (Fig. 3) and this color was absent in the controls. The expression of GFP in M. hyorhinis cells did not appear to interfere with cell growth. Therefore, GFP should also be a vital marker of transformation and cell growth as the pure cultures bearing genetic markers can ease the direct identification of cells and colonies among

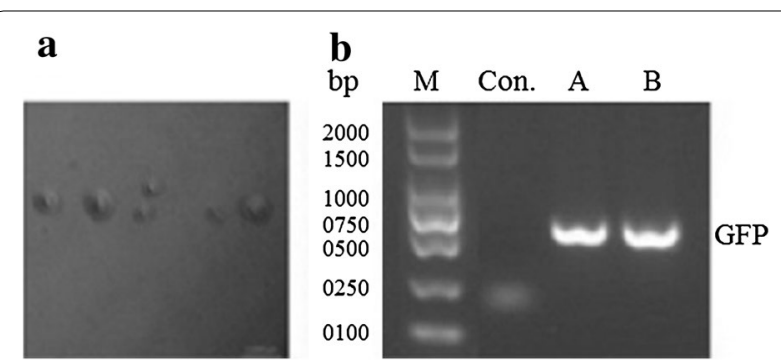

Fig. 2 Detection of pMD18-O/MHRgfp in the transformed cells. M. hyorhinis were transformed with $15 \mu \mathrm{g}$ pMD18-O/MHRgfp and grown in $\mathrm{KM} 2$ medium containing $0.01 \mu \mathrm{g} / \mathrm{ml}$ tetracycline hydrochloride. The same transformants were also plated in KM2-Agar containing $0.01 \mathrm{\mu g} / \mathrm{ml}$ tetracycline hydrochloride and the plate was incubated for 7 days. a Colonies of M. hyorhinis observed under microscopy (scale bar $100 \mu \mathrm{M}$ ). b Transformed mycoplasmas either subcultured in $\mathrm{KM} 2$ medium containing $0.01 \mu \mathrm{g} / \mathrm{ml}$ tetracycline hydrochloride or plated in KM2-Agar containing $0.01 \mathrm{\mu g} / \mathrm{ml}$ tetracycline hydrochloride and a single clone picked and sub-cultured in KM2 medium containing $0.01 \mu \mathrm{g} / \mathrm{ml}$ tetracycline hydrochloride. DNA was extracted from control un-transformed mycoplasmas or from transformed mycoplasmas and presence of pMD18-O/MHRgfp was evaluated by PCR to detect GFP from KM2 (b.A) or from KM2-Agar (b.B). The GFP product of about 750 bp was only detected from the DNA of the transformants mycoplasmas and it was consistent with the predicted sizes of GFP. This band was absent from the controls (un-transformed mycoplasmas)

the population of culture. In related studies, the GFP gene was described as an efficient marker for studying the development and microbe-plant interaction in the tobacco pathogen Phytophthora parasitica var. nicotianae (Bottin et al. 1999). We hypothesize that, tagging $M$. hyorhinis with a plasmid expressing GFP may help to follow the infection process by in vivo imaging if $M$. hyorhinis stably harbored the transformed constructs.

In the present report, the construction of a vector carrying the GFP gene was performed in order to develop a direct method for monitoring gene transfer and expression in M. hyorhinis in which the timing, as well the magnitude of gene expression, is being examined. This visual expression analysis system could also indicate that, the expression of the heterologous genes in M. hyorhinis is feasible. 


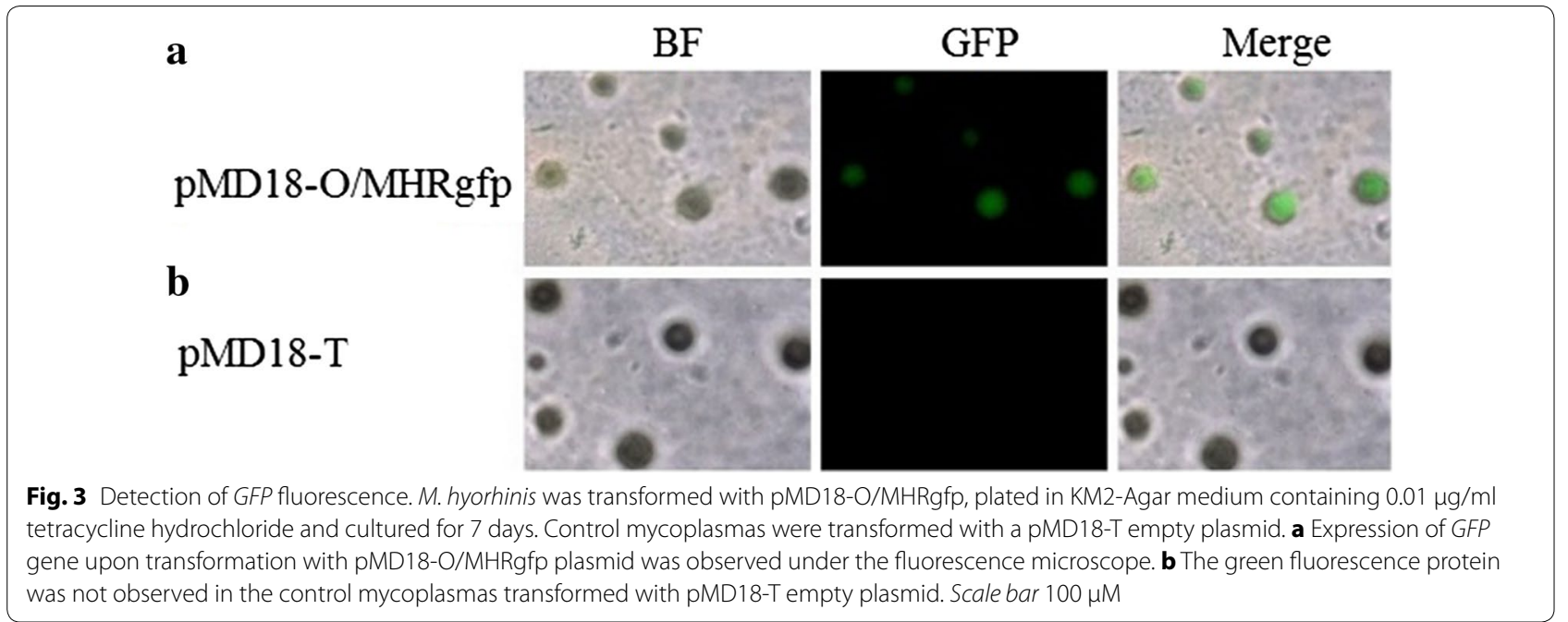

\section{Authors' contributions}

HZAl designed, carried and drafted the manuscript. MJL assisted in the experiment design. QYX, ZXF, YRS and GQS, critically revised and approved the final manuscript. All authors read and approved the final manuscript.

\section{Author details}

${ }^{1}$ Institute of Veterinary Medicine, Jiangsu Academy of Agricultural Sciences, Key Laboratory of Veterinary Biological Engineering and Technology, Ministry of Agriculture, National Research Center for Engineering and Technology of Veterinary Bio-products, Nanjing 210014, China. ${ }^{2}$ College of Veterinary Sciences, University of Nyala, Nyala, Sudan.

\section{Acknowledgements}

The support from postdoctoral fund of Jiangsu Academy of Agricultural Sciences, China (6511318), National Natural Sciences Foundation of China (31550110211, 31300155) and the Natural Sciences Foundation of Jiangsu Province (BK2013070).

\section{Competing interests}

The authors declare that they have no competing interests.

Received: 17 February 2016 Accepted: 17 May 2016

Published online: 17 June 2016

\section{References}

Bottin A, Larche L, Villalba F, Gaulin E, Esquerre-Tugaye MT, Rickauer M (1999) Green fluorescent protein (GFP) as gene expression reporter and vital marker for studying development and microbe-plant interaction in the tobacco pathogen Phythphthora parasitica var. nicotianae. FEMS Microbiol Lett 176(1):51-56

Cordova CM, Lartigue C, Sirand-Pugnet P, Renaudin J, Cunha RA, Blanchard A (2002) Identification of the origin of replication of the Mycoplasma pulmonis chromosome and its use in oriC replicative plasmids. J Bacteriol 184(19):5426-5435

Cubitt AB, Heim R, Adams SR, Boyd AE, Gross LA, Tsien RY (1995) Understanding, improving and using green fluorescent proteins. Trends Biochem Sci 20(11):448-455
Dybvig K, Alderete J (1988) Transformation of Mycoplasma pulmonis and Mycoplasma hyorhinis: transposition of Tn916 and formation of cointegrate structures. Plasmid 20(1):33-41

Ishag HZA, Liu MJ, Yang RS, Xiong QY, Feng ZX, Shao GQ (2016) A replicating plasmid-based vector for GFP expression in Mycoplasma hyopneumoniae. Genet Mol Res. doi:10.4238/gmr.15027832

Liu W, Fang L, Li S, Li Q, Zhou Z, Feng Z, Luo R, Shao G, Wang L, Chen H (2010) Complete genome sequence of Mycoplasma hyorhinis strain HUB-1. J Bacteriol 192(21):5844-5845

Maglennon GA, Cook BS, Matthews D, Deeney AS, Bossé JT, Langford PR, Maskell DJ, Tucker AW, Wren BW, Rycroft AN (2013) Development of a self-replicating plasmid system for Mycoplasma hyopneumoniae. Vet Res 44(1):63

Namiki K, Goodison S, Porvasnik S, Allan RW, Iczkowski KA, Urbanek C, Reyes L, Sakamoto N, Rosser CJ, Tyson DR (2009) Persistent exposure to Mycoplasma induces malignant transformation of human prostate cells. PLoS ONE 4(9):e6872

Razin S, Yogev D, Naot Y (1998) Molecular biology and pathogenicity of mycoplasmas. Microbiol Mol Biol Rev 62(4):1094-1156

Stewart GS, Williams P (1992) Lux genes and the applications of bacterial bioluminescence. J Gen Microbiol 138(7):1289-1300

Xiong Q, Wang J, Ji Y, Ni B, Zhang B, Ma Q, Wei Y, Xiao S, Feng Z, Liu M, Shao $\mathrm{G}$ (2016) The functions of the variable lipoprotein family of Mycoplasma hyorhinis in adherence to host cells. Vet Microbiol 186:82-89

\section{Submit your manuscript to a SpringerOpen ${ }^{\circ}$ journal and benefit from:}

- Convenient online submission

- Rigorous peer review

- Immediate publication on acceptance

- Open access: articles freely available online

- High visibility within the field

- Retaining the copyright to your article

Submit your next manuscript at $\boldsymbol{\nabla}$ springeropen.com 